\title{
The road to clinical use of high-intensity focused ultrasound for liver cancer: technical and clinical consensus
}

\author{
Jean-Francois Aubry ${ }^{1,2}$, Kim Butts Pauly ${ }^{3}$, Chrit Moonen ${ }^{4}$, Gail ter Haar ${ }^{5}$, Mario Ries ${ }^{4}$, Rares Salomir ${ }^{6}$, Sham Sokka ${ }^{7}$, \\ Kevin Michael Sekins ${ }^{8}$, Yerucham Shapira ${ }^{9}$, Fangwei $\mathrm{Y}^{10}{ }^{10}$, Heather Huff-Simonin ${ }^{11}$, Matt Eames ${ }^{11}$, Arik Hananel ${ }^{1{ }^{*}}$, \\ Neal Kassell ${ }^{11}$, Alessandro Napoli' ${ }^{12}$, Joo Ha Hwang ${ }^{13}$, Feng Wu ${ }^{14}$, Lian Zhang ${ }^{15}$, Andreas Melzer ${ }^{16}$, \\ Young-sun Kim ${ }^{17}$ and Wladyslaw M Gedroyc ${ }^{18,19}$
}

\begin{abstract}
Clinical use of high-intensity focused ultrasound (HIFU) under ultrasound or MR guidance as a non-invasive method for treating tumors is rapidly increasing. Tens of thousands of patients have been treated for uterine fibroid, benign prostate hyperplasia, bone metastases, or prostate cancer. Despite the methods' clinical potential, the liver is a particularly challenging organ for HIFU treatment due to the combined effect of respiratory-induced liver motion, partial blocking by the rib cage, and high perfusion/flow. Several technical and clinical solutions have been developed by various groups during the past 15 years to compensate for these problems. A review of current unmet clinical needs is given here, as well as a consensus from a panel of experts about technical and clinical requirements for upcoming pilot and pivotal studies in order to accelerate the development and adoption of focused ultrasound for the treatment of primary and secondary liver cancer.
\end{abstract}

Keywords: Ultrasound, Non-invasive surgery, High-intensity ultrasound, Focused ultrasound, Liver cancer

\section{Current overview and unmet clinical need for treating cancer in and of the liver Introduction}

Although hepatocellular carcinoma and metastatic liver disease require completely separate analysis and study protocols, the technological approach of high-intensity focused ultrasound treatments is similar. Therefore, the two indications will be discussed in parallel as promising pilot studies. In addition, both available guidance methods (ultrasound-guided and MR-guided focused ultrasound) will be considered equally. Both approaches are applicable, and both have advantages and disadvantages.

\section{Primary liver tumors}

The American Cancer Society's 2012 estimate for primary liver and bile duct cancers in the United States amounts to 28,720 new cases and 20,550 deaths [1]. Worldwide,

\footnotetext{
* Correspondence: ahananel@fusfoundation.org

${ }^{11}$ Focused Ultrasound Foundation, Charlottesville, VA, USA

Full list of author information is available at the end of the article
}

liver cancer is the fifth most common cancer in men and the seventh in women. An estimated 748,300 new liver cancer cases occurred during 2008 [2]. Primary Liver cancer rates are the highest in East, Southeast Asia, West and Central Africa [2]. Primary liver cancer occurs most commonly in previously damaged livers, as in cases of viral hepatitis, alcohol abuse, obesity, and exposure to aflatoxin.

Treatment of liver cancer involves multiple strategies used independently, or in combination, depending on the stage of the disease. These include liver replacement therapy, local therapy (resection, ablation), and regional therapy. However, to date, only about $25 \%$ of the patients with primary liver tumors are considered to be suitable candidates for curative treatment. Reasons for patient non-eligibility for curative treatment include factors such as the underlying parenchymal disease state of the liver, tumor size, location, and multi-focality or multi-centricity. HIFU has the potential to improve these percentages by offering a local therapy which may be less limited in terms of patient selection and one that offers a lower threshold for treatment attempt in terms

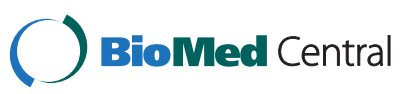


of patient morbidity and complication. For example the 2010 Treatment Guidelines for hepatocellular carcinoma from the American Association for the Study of Liver Disease [3] stated that radiofrequency ablation should be offered to patients with three or fewer primary tumors of less than $3 \mathrm{~cm}$ each, yet HIFU has the potential to target and ablate non-invasively, and in one session, a higher number of lesions with lower treatment-related morbidity.

Patients with more advanced disease are currently offered palliative treatment, including localized transarterial chemoembolization (TACE) or systemic chemotherapy. For this patient population, HIFU can offer the option to combine a low morbidity local therapy.

\section{Liver metastases}

Metastatic liver tumors are more common than primary tumors in the USA. The most common sites of primary tumors that metastasize to the liver are breast, lung, and colon. Some authors have reported hepatic metastases in as many as $40 \%$ to $50 \%$ of adult patients with extrahepatic primary tumors [4].

Colorectal cancer (CRC) is the second most commonly diagnosed cancer in Europe, with an annual incidence of 400,000 cases and an annual mortality of more than 200,000 patients [5]. Almost 70\% of CRC patients develop liver metastases during the course of disease [6].

Curative treatments for patients with liver metastases can be aggressive in terms of the extent of damage to liver tissue since there is usually no underlying liver disease. The existence of a liver metastasis means that the primary cancer is stage IV and also requires systemic therapy, unless contraindicated by other patient factors.

For patients with CRC metastases, all treatment strategies are intended to cure [7] and are only limited by allowing sufficient parenchyma to remain for survival. Surgical resection can offer a 30\%-50\% 5-year and 17\%$26 \% 10$-year survival after a successful procedure $[8,9]$. Yet more than $80 \%$ of the patients are not surgical candidates because of insufficient residual liver tissue, extra-hepatic disease, anatomic constraints of the tumor, or medical comorbidities.

Without treatment, the median survival of patients with colorectal liver metastases is 6-12 months, and the 5-year survival is less than $10 \%$ [10]. Local ablative therapies targeting the liver metastases and surrounding tumor-free margins in patients without extra-hepatic metastases can achieve local tumor control and offer better survival $[11,12]$, even in patients with more than four metastases [13] and in patients with repeated metastases $[14,15]$. Laser-induced thermo therapy, radiofrequency ablation, microwave ablation, cryoablation, and trans-vascular embolization have been applied for curative or palliative ablation of liver metastases [16]. Local ablative techniques result in a delayed and reduced residual intra-hepatic tumor growth and peritoneal tumor spread compared with hepatic resection [17] due to a reduced growth factor expression in comparison to surgical resection $[18,19]$. Also, for patients with liver metastases, HIFU has the potential to offer local therapy which may be less limited in terms of patient selection and one that theoretically should have lower patient morbidity and complication.

\section{Review of clinical trials and technological developments in ultrasonic liver therapy Clinical trials}

HIFU has been explored as a method for non-invasive localized thermal ablation for many years [20,21]. Vallancien et al. [22] was the first to report the use of therapeutic ultrasound to treat the liver. In this study, liver metastases were targeted under ultrasonic guidance with a retractable imaging probe in two patients. Imaging probes have more recently been integrated into the therapeutic heads on clinical devices: 474 patients with primary and metastatic liver cancer have been treated by Wu et al. [23] between 1997 and 2001 with the JC model from Chongqing Haifu (Chongqing, China). Other teams have taken advantage of magnetic resonance (MR) imaging to monitor liver tumor treatments [24,25]. Nevertheless, the ultrasound (US)-guided JC model remains to date the only system with a significant clinical track record in liver and a regulatory approval for liver applications (CE mark and Chinese CFDA).

All these clinical studies suggest that HIFU may be a safe and feasible technique capable of complete tumor ablation, but the same reports describe a significant incidence of skin burns. [23,26-28]. The presence of the rib cage enhances the probability of skin overheating due to the high value of the ultrasonic absorption coefficient of the bone [29] which causes indirect skin heating. In vivo measurements of temperature elevation on pork ribs have been reported by Daum et al. [30] with MR temperature monitoring: temperature elevation during sonication was five times higher on the ribs than in the intercostal space. Moreover, reflection and refraction of the ultrasonic wave by the rib cage affects the focusing [31] and, thus, degrades the efficiency of the treatment at the target.

\section{Technological developments Shadowing effect of the ribs}

In order to minimize the heating effects of the ribs, most of the clinical studies cited previously have taken advantage of sub-costal sonication. Wu et al. [26] proposed the resection of a portion of the ribs overlying the targeted region of the liver in order to provide an acoustic window. It was suggested in the late 1990s that the liver could be treated using a phased array to sonicate between the ribs [32-34], but this could not be tested experimentally at that 
time. Civale et al. [35] recently lowered the temperature of the ribs during sonication by switching off up to three elements of a linearly segmented HIFU transducer. Even though no focal lesions were induced and the energy from the remaining active elements was not sufficient for a clinical application, this study confirmed the proof of concept introduced by McGough et al. [32] and Botros et al. [33]. Multi-element-phased arrays made of hundreds of elements have since been developed [36-39]. Aubry et al. [40] used a 300-element semi-random array to show that time reversal is well suited in focusing through the rib cage for therapeutic applications: the temperature elevation on the rib surface was decreased to a negligible level (a mean of $0.3^{\circ} \mathrm{C}$ ). This can be achieved automatically and noninvasively by computing the decomposition of the time reversal operator based on the backscattered echoes $[41,42]$. Such a technique makes it possible to focus between the ribs and not through the ribs. This can also be achieved by physical blocking using a mask [43].

\section{Breathing motion}

Another medical and technical characteristic of ultrasonic treatment of the liver is that respiratory movement affects the precision and the efficiency of all extracorporeal treatments-HIFU as well as radiotherapy. Several studies [44-47] have shown that abdominal organs can move up to $20 \mathrm{~mm}$ during a respiratory cycle, reaching speeds of up to $15 \mathrm{~mm} / \mathrm{s}$.

(a) Breath holding: One solution is to have the patient undergo ventilator-controlled breath-holds while under general anesthesia. This has been used effectively in small patient studies $[48,49]$.

(b)MR-based motion tracking: Alternatively, a technologically more difficult solution is to steer the beam during continuous breathing. This requires tissue-motion tracking, and a variety of methods have been investigated for tracking liver motion in the MR system. Navigator echoes have been investigated [50]. de Senneville et al. [51] proposed a technique based on an analytical model of the main global motion defined during a pretreatment procedure. The average motion is then estimated and used in order to anticipate the motion during treatment. Ries et al. [52] proposed tracking the target position in the image plane with $2 \mathrm{D}$ optical flow-based image registration, while out-of-plane motion is compensated by dynamic slice tracking. This technique allows sufficient temporal resolution and precision but is very sensitive to the tracking frequency and beam steering latency.

(c) US-based motion tracking: For US-guided HIFU, ultrasound-based techniques have been shown to be able to track the $3 \mathrm{D}$ motion of biological tissues locally [53-56]. Such an approach is based on tracking temporal shifts in the backscattered RF signals, resulting from the displacements of the tissues. The main advantage of the ultrasound-based method is the high penetration rate of ultrasound in the human body and its real-time capabilities. Hence, the natural ultrasonic scatterers in biological tissue can be used as markers to track the local motion of tissues located deep within organs.

(d)Motion compensation by electronic beam steering: Once the 3D movement of the organ is measured, the ultrasonic beam can be electronically steered in order to compensate for this and to follow the tissue motion in real time. Marquet et al. [57] achieved motion compensation ten times per second by interleaving ultrasonic motion detection during the first $20 \mathrm{~ms}$, followed by electronic beam steering calculation and hardware phase adjustment (10 ms) and 70-ms high-intensity sonication, allowing a 70\% duty cycle while tracking the organ. Two studies pulled together the required technologies of motion tracking, beam steering, and MR thermometry to demonstrate the production of HIFU lesions during continuous breathing [58,59].

\section{Monitoring}

(a) MR temperature monitoring in the presence of motion: In order to work, the MR thermometry method must be insensitive to respiratory motion [60]. This requires that both the thermometry processing method and the acquired data are robust in the presence of such movement. For the processing method, multi-baseline [50,51,61,62], referenceless [63-65] and hybrid multi-baseline/ referenceless [66] techniques have been developed. With these techniques available in processing the thermometry data, the acquired data has been shown to be robust in the presence of respiratory-like motion in a phantom [67] and a pig model $[58,59]$.

(b)US monitoring in the presence of motion: Most clinical studies in liver have been performed with $\mathrm{B}$ mode ultrasonic monitoring [23,26-28] of a hyperechogenic signature of the treated area. A rate of 20 to 50 frames per second can be achieved, so that such monitoring is not affected by the liver motion. Nevertheless, liver motion has a major impact on US-based temperature monitoring as this relies on tracking apparent displacements due to the heat-related change of the speed of sound $[68,69]$. Such apparent displacement and liver motion are superimposed, making it difficult to differentiate between each effect. Elastography-based temperature 
monitoring [70] might be the most practical way of achieving US temperature monitoring in the liver.

\section{Unmet needs}

The current unmet need is to provide non-invasive, low morbidity, localized tissue destruction to the significant patient population that is currently being offered palliative treatment. HIFU should be able to provide this due to its non-invasive and highly precise nature. HIFU can be used in close proximity to sensitive structures, and it has the potential to target multiple lesions without the need for multiple incisions or needle insertions (which may cause bleeding, infection, and/or tumor spread). Focused ultrasound also has the potential to facilitate focal targeted drug release which in the future may be an option to enhance chemotherapy.

\section{Pilot study consensus}

A pilot study should address the feasibility and safety of localized tissue destruction using HIFU and provide the information needed to design a pivotal study. The recommendation of the assembled quorum is to choose patients with localized liver lesions who are scheduled for surgery and to treat these patients using HIFU before the surgery, (i.e., ablate-and-resect study). This approach can provide the following outcomes:

(1)Short-term safety: All patients would be followed for 1 week following their HIFU ablation procedure to record any immediate post-procedural adverse effects (such as bleeding, damage to bowel or adjacent organs, and near-field skin/fat/muscle burns).

(2) Post-treatment radiological follow-up data: Following treatment, patients would be imaged by contrast-enhanced MR imaging and/or computed tomography (CT or PET CT if available) to record the post-treatment appearance of the treated lesion, to correlate it with pathological findings, and to asses targeting accuracy.

(3) Post-treatment pathological findings: The excised specimen would be used as a gold standard in an analysis which evaluates correlation between the planned, imaged, and ablated tissue, and would confirm the completeness of the tissue destruction.

Since the goal of the pilot study is to establish evidence for the efficacy and safety of HIFU for localized thermal ablation of tissue in the liver, the patient population could include both primary and secondary liver tumor patients. However, it would be advisable that the first several patients recruited and treated in this study would be CRC patients in order to reduce the risk of introducing patient/ liver-related complications due to the underlying liver disease in primary liver tumor patients.

The proposed pilot study is a single-arm ablate-andresect study, targeting patients with primary or secondary liver cancer who are candidates for surgical resection. After enrollment, the patients would undergo HIFU treatment and be followed for a period of 1 week. After 1 week, the treated lesion would be excised and sent for pathological analyses. A potential approach to gradually increasing total dose used could be in the initial treatments to partially ablate the targeted tumor tissue and (2) in later treatments to completely ablate the tumors, including a tumor margin.

\section{Pivotal study}

The pivotal study should target the patient population identified in the unmet need section: primary liver cancer patients who are not candidates for surgical resection and who are receiving palliative treatment. This patient population could include patients with more than three lesions, patients with one lesion bigger than $5 \mathrm{~cm}$, patients with ascites, or patients with lesions close to major blood vessels or other structures that make resection or radiofrequency ablation difficult or impossible. The specifics of what population to include from the list above would take into consideration results and learned lessons on HIFU capabilities in terms of accuracy and treatment speed as were demonstrated in the pilot study. We suggest a double-arm study where the control arm would get TACE and the test arm would get TACE and HIFU. The sample size would be determined by existing evidence in the literature regarding the efficacy of such combination treatment [71].

The rationale for the study is the need to avoid the risk of withholding existing therapy from a severely ill patient population, while considering the near-term reality of where to maximize clinical benefit; it is expected that these patients would receive combination therapy anyway.

An acceptable procedure, to be done in preparation for the HIFU ablation session, is to insert saline or another fluid into the peritoneal cavity to move the bowels away from the targeted area or into the pleural cavity to move the lungs away from the acoustic pathway. This procedure can be done if necessary for safety, but should not be part of the routine.

Follow-up would include imaging, measurement of alpha fetoprotein levels (although effectiveness may be compromised due to TACE), liver function testing, and record of disease-related events including local, regional and distant recurrences, disease-specific survival, diseasefree survival, and overall survival.

As a future second step, it is envisioned that a three-arm study comparing the safety and efficacy of TACE alone, 
HIFU alone, and the combination of HIFU and TACE will be conducted. This second, three-arm study would be needed to obtain regulatory approval for the usage of HIFU ablation of primary liver tumor as a stand-alone therapy. A separate pivotal trial for the metastatic liver disease indication would be required.

\section{Minimal technical specifications of a HIFU system for the treatment of liver tumors}

The many aspects and technological improvements in HIFU technology, which are required to treat liver cancer have been researched for years ('Technological developments' section). However, as part of our recommendation, we tried to narrow the technical specifications to the minimum required for a future or existing HIFU system to be commercially viable in terms of patient selection, quality and cost of treatment, and technological availability and cost. We have identified the following minimal requirements:

- Treatment rate should be at least $1 \mathrm{cc}$ of ablated tissue per minute.

- The entire procedure should last 4 hours or less (and has a potential of reducing time to 2 hours).

- The system should be able to target at least $80 \%$ of the liver volume in a typical patient.

- The system should be able to transmit energy either in between, below, or through the ribs without damaging the ribs or causing a skin burn.

- The system should have an imaging guidance system for targeting tumors.

- It would be beneficial to have closed loop thermometry (MR-based or otherwise)

- It would be beneficial to have beam steering tissue tracking to enable the patient to breathe freely, but this is not a 'must have' feature, and carrying out treatment with the patient under general anesthesia using forced apnea is acceptable.

Each of these components has been developed separately or by academic research groups.

\footnotetext{
Competing interests

JFA, KBP, GHH, RS, AN, JHH, FW, LZ, YK, and WMG declare no competing interests. CM and MR acknowledge research collaboration with Philips Healthcare. SS is currently employed by Philips Healthcare. KMS is currently employed by Siemens Healthcare. YS is currently employed by InSightec. FY is currently employed by Chongqing HAIFU. HHS and ME are currently employed by the Focused Ultrasound Foundation. AH and NK are currently employed by the Focused Ultrasound Foundation and share holders at InSightec. AM acknowledges research collaboration with GE and InSightec and funding by European Union.
}

\section{Authors' contributions}

All the authors participated in at least one of the two workshops organized by the focused ultrasound foundation to establish this consensus. The minutes of the meetings were collected by ME. First draft was written by $\mathrm{AH}$ and JFA. Active editing and commenting were done by YSK, LZ, AM, WMG,
$\mathrm{CM}, \mathrm{KBP}, \mathrm{GTH}, \mathrm{RS}, \mathrm{KMS}$, and SS. All authors read and approved the final manuscript.

\section{Acknowledgments}

The authors wish to thank the Focused Ultrasound Foundation for initiating and funding the workshop from which this work started. The authors thank Jill W. Roberts, M.S., for her assistance in meeting coverage and in preparing the initial version of this manuscript. AM acknowledges research collaboration with GE and InSightec and funding by European Union FP7/ 2007-2013 for MRgFUS projects under grant agreement nos.: 270186 and 230674

\section{Author details}

${ }^{1}$ Institut Langevin, ESPCI ParisTech, CNRS UMR 7587, INSERM U979, Université Denis Diderot, Paris VII, Paris, France. 'Department of Radiation Oncology, University of Virginia, Charlottesville, VA, USA. ${ }^{3}$ Radiological Sciences Laboratory, Stanford University School of Medicine, Palo Alto, CA, USA. ${ }^{4}$ Imaging Division, University Medical Center Utrecht, Amsterdam, The Netherlands. ${ }^{5}$ Division of Radiotherapy and Imaging, The Institute of Cancer Research, Royal Marsden Hospital, Sutton, Surrey, UK. 'Faculty of Medicine, University of Geneva, Geneva, Switzerland. ${ }^{7}$ Philips Healthcare, Boston, MA, USA. ${ }^{8}$ Ultrasound Innovations Applications, Siemens Healthcare, Issaquah, WA, USA. ${ }^{9}$ InSightec Ltd, 5 Nahum Heth Street, Haifa, Israel. ${ }^{10}$ Chongqing Haifu Medical Technology Co., Ltd, Chongqing, China. ${ }^{11}$ Focused Ultrasound Foundation, Charlottesville, VA, USA. ${ }^{12}$ University of Rome, La Sapienza, Rome, Italy. ${ }^{13}$ Digestive Disease Center, University of Washington, Seattle, WA, USA. ${ }^{14}$ Institute of Ultrasonic Engineering in Medicine, Chongqing Medical University, Chongqing, China. ${ }^{15}$ Clinical Center for Tumor Therapy, Second Affiliated Hospital of Chongqing University of Medical Sciences, Chongqing, China. ${ }^{16}$ Institute for Medical Science and Technology, University of Dundee, Dundee, Scotland, UK. ${ }^{17}$ Department of Radiology, Samsung Medical Center, Sungkyunkwan University School of Medicine, Seoul, South Korea. ${ }^{18}$ Department of Medicine, Imperial College, South Kensington Campus, Exhibition Rd, London SW7 2AZ, UK. ${ }^{19}$ Saint Mary's Hospital, Praed St, W2 1NY, London, UK.

Received: 15 March 2013 Accepted: 12 June 2013

Published: 1 August 2013

\section{References}

1. American Cancer Society. Cancer facts and figures 2012. Atlanta, GA: American Cancer Society; 2012. [cited 2012 September 6]. Available from: http://www.cancer.org/Research/CancerFactsFigures/CancerFactsFigures/ cancer-facts-figures-2012.

2. American Cancer Society. Global cancer facts and figures. Atlanta, GA: 2nd edition. American Cancer Society; 2012. [cited 2012 September 6]. Available from: http://www.cancer.org/Research/CancerFactsFigures/GlobalCancer FactsFigures/global-facts-figures-2nd-ed.

3. Bruix J, Sherman M. Management of hepatocellular carcinoma: an update. Alexandria (VA, USA): American Association for the Study of Liver Diseases; 2010. [cited 2012 September 6]. Available from: http://guidelines.gov/ content.aspx?id=23927.

4. Ananthakrishnan A, Gogineni V, Saeian K. Epidemiology of primary and secondary liver cancers. Semin Intervent Radiol. 2006; 23(1):47-63.

5. Ferlay J, Autier P, Boniol M, Heanue M, Colombet M, Boyle P. Estimates of the cancer incidence and mortality in Europe in 2006. Ann Oncol. 2007; 18:581-92.

6. Ruers T, Bleichrodt RP. Treatment of liver metastases, an update on the possibilities and results. Eur J Cancer. 2002; 38:1023-33.

7. Vauthey JN, Choti MA, Helton WS. AHPBA/SSO/SSAT Consensus Conference on hepatic colorectal metastases: rationale and overview of the conference. January 25, 2006. Ann Surg Oncol. 2006; 13(10):1259-60.

8. O'Rourke AP, Haemerich D, Prakash P, Converse MC, Mahvi DM, Webster JG. Current status of liver ablation devices. Expert Rev Med Devices. 2007; 4:523-37.

9. Kopetz S, Chang GJ, Overman MJ. Improved survival in metastatic colorectal cancer is associated with adoption of hepatic resection and improved chemotherapy. J Clin Oncol. 2009; 27:3677-83.

10. Bengmark $S$, Hafstrom L. The natural history of primary and secondary malignant tumors of the liver. I The prognosis for patients with hepatic 
metastases from colonic and rectal carcinoma by laparotomy Cancer. 1969; 23:198-202.

11. Konopke R, Roth J, Volk A, Pistorius S, Folprecht G, Zöphel K, Schuetze C, Laniado M, Saeger HD, Kersting S. Colorectal liver metastases: an update on palliative treatment options. J Gastrointestin Liver Dis. 2012; 21:83-91.

12. Vogl TJ, Jost A, Nour-Eldin NA, Mack MG, Zangos S, Naguib NN. Repeated transarterial chemoembolisation by different chemotherapeutic drug combinations followed by MR-guided laser-induced thermotherapy in patients with liver metastases of colorectal carcinoma. Br J Cancer. 2012; 106(7):1274-79.

13. Minagawa M, Makuuchi M, Torzilli G, Takayama T, Kawasaki S, Kosuge T, Yamamoto J, Imamura $\mathrm{H}$. Extension of the frontiers of surgical indications in the treatment of liver metastases from colorectal cancer: long-term results. Ann Surg. 2000; 231:487-99.

14. Nagakura S, Shirai Y, Suda T, Hatakeyama K. Multiple repeat resections of intra- and extrahepatic recurrences in patients undergoing initial hepatectomy for colorectal carcinoma metastases. World J Surg. 2002; 26:141-47

15. Petrowsky H, Gonen M, Jarnagin W, Lorenz M, DeMatteo R, Heinrich S, Encke A, Blumgart L, Fong $Y$. Second liver resections are safe and effective treatment for recurrent hepatic metastases from colorectal cancer: a bi-institutional analysis. Ann Surg. 2002; 235:863-71.

16. Goldberg SN, Grassi CJ, Cardella JF, Charboneau JW, Dodd GD III, Dupuy DE, Gervais DA, Gillams AR, Kane RA, Lee FT Jr, Livraghi T, McGahan J, Phillips DA, Rhim H, Silverman SG, Solbiati L, Vogl TJ, Wood BJ, Vedantham S, Sacks D, Society of Interventional Radiology Technology Assessment Committee and the International Working Group on Image-guided Tumor Ablation. Image-guided tumor ablation: standardization of terminology and reporting criteria. J Vasc Interv Radiol. 2009; 20(Suppl 7):S377-90.

17. Isbert C, Boerner A, Ritz JP, Schuppan D, Buhr HJ, Germer CT. In situ ablation of experimental liver metastases delays and reduces residual intrahepatic tumour growth and peritoneal tumour spread compared with hepatic resection. Br J Surg. 2002; 89(10):1252-59.

18. Slooter $\mathrm{GD}$, Marquet $\mathrm{RL}$, Jeekel J, ljzermans JN. Tumour growth stimulation after partial hepatectomy can be reduced by treatment with tumour necrosis factor alpha. Br J Surg. 1995; 82(1):129-32.

19. Meredith K, Haemmerich D, Qi C, Mahvi D. Hepatic resection but not radiofrequency ablation results in tumor growth and increased growth factor expression. Ann Surg. 2007; 245(5):771-76.

20. Ter Haar G, Coussios C. High intensity focused ultrasound: physical principles and devices. Int J Hyperthermia. 2007; 23(2):89-104.

21. Orsi $F$, Arnone $P$, Chen $W$, Zhang $L$. High intensity focused ultrasound ablation: therapeutic option for solid tumors. J Cancer Res Ther. 2010; 4:414-20.

22. Vallancien G, Harouni M, Veillon B, Mombet A, Praponitch D, Brisset JM, Bougaran J. Focused extracorporeal pyrotherapy: feasibility study in man. J Endourol. 1992; 6(2):173-81. doi:10.1089/end.1992.6.173.

23. Wu F, Wang ZB, Chen WZ. Extracorporeal high intensity focused ultrasound ablation in the treatment of 1038 patients with solid carcinomas in China: an overview. Ultrason Sonochem. 2004; 11(3-4):149-54.

24. Okada A, Murakami T, Mikami K, Onishi H, Tanigawa N, Marukawa T, Nakamura $\mathrm{H}$. A case of hepatocellular carcinoma treated by MR-guided focused ultrasound ablation with respiratory gating. Magn Reson Med Sci. 2006; 5(3):167-71.

25. Kopelman D, Inbar Y, Hananel A, Freundlich D, Castel D, Perel A, Greenfeld A, Salamon T, Sareli M, Valeanu A, Papa M. Magnetic resonance-guided focused ultrasound surgery (MRgFUS): ablation of liver tissue in a porcine model. Eur J Radiol. 2006; 59:157-62.

26. Wu F, Zhi-Biao W, Wen-Zhi C, Hui Z, Jin B, Jian-Zhong Z, Ke-Quan L, ChengBing J, Fang-Lin $X$, Hai-Bing $S$. Extracorporeal high intensity focused ultrasound ablation in the treatment of patients with large hepatocellular carcinoma. Ann Surg Oncol. 2004; 11:1061-69.

27. Kennedy JE, Wu F, ter Haar GR. High-intensity focused ultrasound for the treatment of liver tumours. Ultrasonics. 2004; 42:931-35.

28. Li JJ, Xu GL, Gu MF. Complications of high intensity focused ultrasound in patients with recurrent and metastatic abdominal tumors. World J Gastroenterol. 2007: 13(19):2747-51.

29. Goss SA, Frizzell LA, Dunn F. Ultrasonic absorption and attenuation in mammalian tissues. Ultrasound Med Biol. 1979; 5(2):181-86.

30. Daum DR, Smith NB, King R, Hynynen K. In vivo demonstration of noninvasive thermal surgery of the liver and kidney using an ultrasonic phased array. Ultrasound Med Biol. 1999; 25(7):1087-98.
31. Kennedy JE, Clarke RL, ter Haar GR. The effects of absorbers such as ribs in the HIFU beam-path on the focal profile. Second International Symposium on Therapeutic Ultrasound. 2002:185-92.

32. McGough RJ, Kessler ML, Ebbini ES, Cain CA. Treatment planning for hyperthermia with ultrasound phased arrays. IEEE Trans Ultrason Ferroelectr Frea Contr. 1996; 43:1074-84.

33. Botros YY, Volakis JL, VanBaren P, Ebbini ES. A hybrid computational model for ultrasound phased-array heating in presence of strongly scattering obstacles. IEEE Trans Biomed Eng. 1997; 44:1039-50.

34. Botros YY, Ebbini ES, Volakis JL. Two-step hybrid virtual array-ray (VAR) technique for focusing through the rib cage IEEE. Trans Ultrason Ferroelect Freq Contr. 1998; 45:989-99.

35. Civale J, Clarke R, Rivens I, ter Haar G. The use of a segmented transducer for rib sparing in HIFU treatments. Ultrasound Med Biol. 2006; 32(11):1753-61.

36. Daum DR, Buchanan MT, Fjield T, Hynynen K. Design and evaluation of a feedback based phased array system for ultrasound surgery. IEEE Trans Ultrason Ferroelectr Freq Contr. 1998; 45:43-8.

37. Chapelon JY, Cathignol D, Cain C, Ebbini E, Kluiwstra JU, Sapozhikov O, Fleury G, Berriet R, Chupin L, Guey JL. New piezoelectric transducers for therapeutic ultrasound. Ultrasound Med Biol. 2000; 26(1):153-59.

38. Pernot M, Aubry JF, Tanter M, Thomas JL, Fink M. High power transcranial beam steering for ultrasonic brain therapy. Phys Med Biol. 2003; 48(16):2577-89.

39. Ebbini ES, Yao H, Shrestha A. Dual-mode ultrasound phased arrays for image-guided surgery. Ultrasonic Imaging. 2006; 28(2):65-82.

40. Aubry JF, Pernot M, Marquet F, Tanter M, Fink M. Transcostal highintensity-focused ultrasound: ex vivo adaptive focusing feasibility study. Phys Med Biol. 2008; 53:2937-51.

41. Cochard E, Prada C, Aubry JF, Fink M. Ultrasonic focusing through the ribs using the DORT method. Med Phys. 2009; 36(8):3495-503.

42. Cochard E, Aubry JF, Tanter M, Prada C. Adaptive projection method applied to three-dimensional ultrasonic focusing and steering through the ribs. J Acoust Soc Am. 2011; 130(2):716-23.

43. Salomir R, Petrusca L, Auboiroux V, Muller A, Vargas MI, Morel DR, Goget T, Breguet R, Terraz S, Hopple J, Montet X, Becker CD, Viallon M. Magnetic resonance-guided shielding of prefocal acoustic obstacles in focused ultrasound therapy: application to intercostal ablation in liver. Invest Radiol. 2013; 48(6):366-80.

44. Bryan PJ, Custar S, Haaga JR, Balsara V. Respiratory movement of the pancreas: an ultrasonic study. J Ultra Med. 1984; 3:317-20.

45. Ross CS, Hussey DH, Pennington EC, Stanford W, Doombos JF. Analysis of movement of intrathoracic neoplasms using ultrafast computerized tomography. Int J Radiat Oncol Biol Phys. 1990; 18:671-77.

46. Korin HW, Ehman RL, Riederer SJ, Felmlee JP, Grimm RC. Respiratory kinematics of the upper abdominal organs: a quantitative study. Magn Reson Med. 1992; 23(1):172-78.

47. Davies SC, Hill AL, Holmes RB, Halliwell M, Jackson PC. Ultrasound quantitation of respiratory organ motion in the upper abdomen. Br J Radiol. 1994; 67:1096-102.

48. Visioli AG, Rivens IH, ter Haar GR, Horwich A, Huddart RA, Moskovic E, Padhani A, Glees J. Preliminary report of a phase I dose escalation study using focused ultrasound in the treatment of localised tumours. Eu J Ultrasound. 1999; 9:11-8.

49. Gedroyc WM. New clinical applications of magnetic resonance-guided focused ultrasound. Top Magn Reson Imaging. 2006; 17(3):189-94.

50. Vigen KK, Daniel BL, Pauly JM, Butts K. Triggered, navigated, multi-baseline method for proton resonance frequency temperature mapping with respiratory motion. Magn Reson Med. 2003; 50(5):1003-10.

51. de Senneville BD, Mougenot C, Moonen CT. Real-time adaptive methods for treatment of mobile organs by MRI-controlled high-intensity focused ultrasound. Magn Reson Med. 2007; 57:319-30.

52. Ries M, de Senneville BD, Roujol S, Berber Y, Quesson B, Moonen CT. Realtime 3D target tracking in MRI guided focused ultrasound ablations in moving tissues. Magn Reson Med. 2010; 64:1704-12.

53. Hsu A, Miller NR, Evans PM, Bamber JC, Webb S. Feasibility of using ultrasound for real-time tracking during radiotherapy. Med Phys. 2005; 32:1500-14

54. Tanter M, Pernot M, Aubry JF, Montaldo G, Marquet F, Fink M. Compensating for bone interfaces and respiratory motion in high intensity focused ultrasound. Int J Hyperthermia. 2007; 23(2):141-51. 
55. Harris EJ, Miler NR, Bamber JC, Evans PM, Symonds-Tayler JRN. Performance of ultrasound based measurements of 3D displacement using a curvilinear probe for organ motion tracking. Phys Med Biol. 2007; 52:5683-703.

56. Schwartz BM, McDannold NJ. Ultrasound echoes as biometric navigators. Magn Reson Med. 2013; 69(4):1023-33.

57. Marquet F, Aubry JF, Pernot M, Fink M, Tanter M. Optimal transcostal highintensity focused ultrasound with combined real-time 3D movement tracking and correction. Phys Med Biol. 2011; 56(22):7061-80

58. Quesson B, Laurent C, Maclair G, de Senneville BD, Mougenot C, Ries M, Carteret T, Rullier A, Moonen CT. Real-time volumetric MRI thermometry of focused ultrasound ablation in vivo: a feasibility study in pig liver and kidney. NMR Biomed. 2011; 24(2):145-53.

59. Holbrook AB, Ghanouni P, Santos JM, Dumoulin C, Medan Y, Butts Pauly K. Respiration based steering for high intensity focused ultrasound liver ablation. Magn Reson Med. In press.

60. De Senneville BD, Ries M, Bartels LW, Moonen $C T$, In Interventional Magnetic Resonance Imaging. MRl-guided high-intensity focused ultrasound sonication of liver and kidney. New York: Springer: Edited by Kahn T, Busse H; 2012: p. 349-66.

61. Vigen KK, Jarrard J, Rieke V, Frisoli J, Daniel BL, Butts PK. In vivo porcine liver radiofrequency ablation with simultaneous MR temperature imaging. J Magn Reson Imaging. 2006; 23(4):578-84.

62. Shmatukha AV, Bakker CJ. Correction of proton resonance frequency shift temperature maps for magnetic field disturbances caused by breathing. Phys Med Biol. 2006; 51(18):4689-705.

63. Rieke V, Vigen KK, Sommer G, Daniel BL, Pauly JM, Butts K. Referenceless PRF shift thermometry. Magn Reson Med. 2004; 51(6):1223-31.

64. Kuroda K, Kokuryo D, Kumamoto E, Suzuki K, Matsuoka Y, Keserci B. Optimization of self-reference thermometry using complex field estimation. Magn Reson Med. 2006; 56(4):835-43. A published erratum appears in Magn Reson Med 2007, 57(4):812.

65. Salomir R, Viallon M, Kickhefel A, Roland J, Morel DR, Petrusca L, Auboiroux V, Goget T, Terraz S, Becker CD, Gross P. Reference-free PRFS MRthermometry using near-harmonic 2-D reconstruction of the background phase. IEEE Trans Med Imaging. 2012; 31(2):287-301.

66. Grissom WA, Rieke V, Holbrook AB, Medan Y, Lustig M, Santos J, McConnell MV, Pauly KB. Hybrid referenceless and multibaseline subtraction MR thermometry for monitoring thermal therapies in moving organs. Med Phys. 2010; 37(9):5014-26.

67. Holbrook AB, Santos JM, Kaye E, Rieke V, Pauly KB. Real-time MR thermometry for monitoring HIFU ablations of the liver. Magn Reson Med. 2010; 63(2):365-73.

68. Pernot M, Tanter M, Bercoff KR, Waters M. Fink Temperature estimation using ultrasonic spatial compound imaging. IEEE Ultras Ferr Freq Contr. 2004; 51:5.

69. Liu D, Ebbini ES. Real-time 2-D temperature imaging using ultrasound IEEE. Trans Biomed Eng. 2010; 57(1):12-6.

70. Sapin-de Brosses E, Pernot M, Tanter M. The link between tissue elasticity and thermal dose in vivo. Phys Med Biol. 2011; 56(24):7755-65.

71. Wu F, Wang ZB, Chen WZ, Zou JZ, Bai J, Zhu H, Li KQ, Jin CB, Xie FL, Su HB. Advanced hepatocellular carcinoma: treatment with high-intensity focused ultrasound ablation combined with transcatheter arterial embolization. Radiology. 2005; 235(2):659-67.

doi:10.1186/2050-5736-1-13

Cite this article as: Aubry et al:: The road to clinical use of high-intensity focused ultrasound for liver cancer: technical and clinical consensus. Journal of Therapeutic Ultrasound 2013 1:13.

\section{Submit your next manuscript to BioMed Central and take full advantage of:}

- Convenient online submission

- Thorough peer review

- No space constraints or color figure charges

- Immediate publication on acceptance

- Inclusion in PubMed, CAS, Scopus and Google Scholar

- Research which is freely available for redistribution

Submit your manuscript at www.biomedcentral.com/submit 